УДК 378.014(47+57)"1901/1906”(045)

\title{
E.Ю. Жарова
}

\section{ПРОФЕССОРСКАЯ КОРПОРАЦИЯ И РЕФОРМИРОВАНИЕ СИСТЕМЫ ОБУЧЕНИЯ В УНИВЕРСИТЕТАХ НА РУБЕЖЕ ХIX-XX ВЕКОВ}

\begin{abstract}
В конце XIX - начале XX в. министерство народного просвещения уже не могло проводить реформы, не опираясь на мнение представителей профессорской корпорации. Крупнейшие совещания, организованные министерством с целью выяснить точки зрения профессоров по самым актуальным вопросам университетской жизни, состоялись в 1901 и 1906 гг. Целью этих совещаний был пересмотр университетского устава 1884 г., однако ни в первом, ни во втором случае новый устав принят не был. Материалы первого совещания оказались под сукном в министерстве, а вот по результатам второго совещания был провозглашён переход на предметную систему обучения. В условиях того времени (1906), наряду с другими послаблениями в сфере университетского управления, это был значительный шаг вперёд к университетской автономии и свободе обучения, выраженной в предметной системе. В статье проводится анализ мнений профессоров университетов Российской империи, полученных в ходе этих двух совещаний и отражающих точки зрения представителей профессорской корпорации на предмет реформирования системы обучения.
\end{abstract}

Ключевые слова: профессора, университеты, Российская империя, реформа, предметная система обучения.

DOI: $10.35634 / 2412-9534-2020-30-4-607-615$

Несмотря на то, что историография университетов Российской империи имеет давнюю традицию, профессорская корпорация как объект изучения оказалась в фокусе исследователей относительно недавно. При этом можно заметить смещение исследовательского интереса от процессов формирования профессорской корпорации в первой половине XIX в. [4; 7] к созданию коллективного портрета профессоров отдельных университетов $[9 ; 18 ; 20 ; 24]$, а затем и к изучению профессорскопреподавательской корпорации как социально-профессиональной группы $[6 ; 15 ; 21]$ и её взаимодействия с властью [19].

Профессорская корпорация начала влиять на образовательные реформы уже во второй четверти XIX в., когда её представители приняли участие в создании проектов университетских уставов [13]. Однако наиболее активное участие в обсуждении образовательных инициатив власти представители профессорской корпорации начали принимать во второй половине XIX в. На рубеже XIX-XX вв. университеты столкнулись с масштабными студенческими беспорядками, и власть не только вновь обратилась к профессорской корпорации за мнением, но и оказалась готовой пойти на значительные уступки. Поэтому этот период является знаковым для анализа возрастающего влияния профессорской корпорации на проведение необходимых ей реформ.

К моменту появления устава 1884 г. в университетах Российской империи господствовала курсовая система обучения, то есть на каждом курсе студенты изучали определённое количество предметов, по которым впоследствии сдавали экзамены. Перечень дисциплин мог отличаться от университета к университету, при этом чаще всего оставался неизменными в отдельно взятом университете на протяжении нескольких лет. Устав 1884 г. попытался сломать эту систему, отменив ежегодные экзамены и введя итоговый государственный экзамен. Путём введения полугодий министерство попыталось удлинить весеннее полугодие и дать студентам возможность выбора изучаемых предметов за счёт разнообразия профессорских и приват-доцентских курсов, то есть ввести подобие предметной системы.

Предметная система обучения, в отличие от курсовой, предполагала более лабильный подход к обучению за счёт предоставления возможности выбирать изучаемые курсы и их последовательность, более лабильной была и система экзаменов, которые предполагалось сдавать за полукурс (после второго года обучения, причём без привязки ко времени, по степени готовности студентов) и по результатам всего курса обучения (эта система была принята в Дерптском университете). Однако попытка ввести подобный порядок экзаменов с треском провалилась в первый же год сдачи итогового государственного экзамена (1888), что повлекло за собой в целом возврат к прежней системе экзаменов, а выбор последовательности изучения курсов авторами устава 1884 г. к введению не предполагался, так как университетам было предписано составить учебные планы и отправить их на утверждение в министерство. 
Так, в циркуляре от 12 февраля 1885 г., разъясняющем порядок составления учебных планов, министр И. Д. Делянов писал: «Что касается до нормального порядка изучения наук, то он должен быть указан в учебных планах распределением подлежащих изучению наук по отдельным учебным полугодиям. При этом не могу не выразить желания, чтобы указания эти были как можно менее стеснительны для студентов и чтобы им предоставлен был возможно больший простор в выборе предметов для изучения в каждое данное полугодие: стеснение в этом отношении может быть допускаемо единственно лишь в тех случаях, когда для успешного и плодотворного изучения какой-либо науки необходимо, по самому существу дела, предварительное изучение других наук факультета» [10, ф. 977, оп. ФМФ. д. 1036, л. 11об].

Важным посылом для составления как можно большего числа учебных планов по одному факультету было желание министерства более равномерно распределить студентов по аудиториям, чтобы не допускать их скученности с целью «правильного наблюдения за их научными занятиями». Это было связано с тем, что по замыслу министерства студенты, занятые наукой, не будут участвовать в антиправительственных выступлениях. С этой же целью приоритетными были объявлены практические занятия студентов.

В фонде И. Д. Делянова в РГИА сохранились заметки министра с выражением его мнения о сущности свободы преподавания, к которой он относился довольно критично. Называя свободу преподавания в Дерптском университете только «концепцией свободы» из-за того, что «в девяти из десяти случаев профессор, преподающий предмет, есть вместе с тем и экзаменатор по этому предмету» [16, ф. 1604, оп. 1, д. 238, л. 1об], что делало студента зависимым от профессора, он считал, что свобода преподавания приведёт к тому, что студенты не будут оканчивать курс в срок. Более того, эта система рассчитана на гениев, а в университете учатся средние студенты. А вот свобода учения вызывала у него не такие отрицательные мысли: он писал о том, что свобода учения способна сблизить студента и профессора, «ибо первых побудит обращаться к последним» $[16$, ф. 1604, оп. 1, д. 238, л. 63], и поможет преодолеть студентам лень. Министр считал, что «при свободе учения легко устраивается преподавание демонстративных и практических предметов и занятий с устранением большого скопления студентов» $[16$, ф. 1604 , оп. 1 , д. 238, л. 68$]$, о чём и было указано в министерском циркуляре.

То, что пытались сделать в университетах после 1884 г., можно назвать попыткой перехода на предметную систему, умолчав о том, какой усечённой представлял себе И. Д. Делянов эту самую предметную систему. Несмотря на то, что формально устав предоставлял возможность преподавателям объявлять параллельные курсы и вести занятия по обязательным и дополнительным предметам, а студентам - выбирать профессорский или приват-доцентский лекционный и практический курс, на самом деле, как подчёркивал С. В. Рождественский, «такой порядок не устанавливал действительной свободы преподавания и учения» [17, с. 620]. При этом профессорская корпорация разделилась на две группы: желавших возврата к старой курсовой системе и считавших лучшим вариантом полный переход на предметную систему обучения, что предполагало также изменение порядка проведения экзаменов. В конце концов, победили сторонники перехода на предметную систему обучения, реализация которого, впрочем, не оказалась успешной, так как система государственных экзаменов в университетах осталась прежней, а диплом всё также был связан с преимуществами в получении чина по Табели о рангах.

В отношении экзаменов очень часто высказывались мнения в пользу прежнего порядка, существовавшего до принятия устава 1884 г. Так, химик А. М. Зайцев в 1898 г. предлагал заменить сочинение у студентов 3-го курса (5 и 6 семестров) и вернуть прежний порядок предоставления сочинения по окончании курса обучения, а также организовать чтение большинства курсов в первые два года обучения со сдачей обязательного экзамена по окончании преподавания каждого курса $[16$, ф. 733 , оп. 150 , д. 1557 , л. 30].

Следует отметить, что А. М. Зайцев выражал точку зрения большинства профессоров, считавших, что сочинение следует предоставлять после окончания курса. Например, профессор геологии Казанского университета А. А. Штукенберг просил установить экзамены на всех трёх курсах (в то время студенты 3-го курса экзамены не сдавали), что, по его мнению, «дало бы студентам возможности вести свои занятия гораздо более правильно и равномерно и переходить на 4 курс достаточно ориентированными в общих естественно-исторических курсах» $[16$, ф. 733 , оп. 150, д. 1557, л. 128]. Этого же мнения придерживался Н. А. Бунге, профессор химии Киевского университета [16, ф. 733, оп. 150, д. 1557, л. 
Профессорская корпорация и реформирование системы обучения...

163об]. Однако вопросы о контроле над занятиями студентов были тесно связаны с существующей системой обучения, поэтому многие профессора, выражавшие недовольство системой экзаменов, видели возможность её реформирования посредством реформирования системы обучения в целом.

В самом конце XIX в., когда министерство задумалось о пересмотре устава 1884 г. в связи с многочисленными студенческими выступлениями, в университеты были разосланы 18 вопросов, касающиеся разных животрепещущих тем университетской жизни, среди которых были и вопросы организации учебного процесса.

В табл. обобщены мнения разных университетов по поводу реформирования системы экзаменов, в том числе итогового государственного [16, ф. 733, оп. 154, д. 267, л. 691-718об].

Свод мнений университетов по вопросам, предложенным министром народного просвещения (1901 г.)

\begin{tabular}{|c|c|c|}
\hline \multirow{2}{*}{ Университет } & \multicolumn{2}{|c|}{ Вопросы } \\
\hline & О курсовых экзаменах & О государственных экзаменах \\
\hline Петербургский & Передать на усмотрение факультетов & $\begin{array}{c}\text { Вернуть итоговые экзамены согласно } \\
\text { уставу } 1863 \text { г. }\end{array}$ \\
\hline Московский & $\begin{array}{c}\text { Передать на усмотрение факультетов, } \\
\text { но приурочить к учебным планам с тем, что- } \\
\text { бы студенты приступали к сдаче не позднее } \\
\text { двух лет после поступления }\end{array}$ & Отменить государственные экзамены \\
\hline Казанский & Восстановить & Отменить государственные экзамены \\
\hline Харьковский & $\begin{array}{l}\text { Передать на усмотрение факультетам, при- } \\
\text { урочить к учебным планам с определенной } \\
\text { последовательностью и числом экзаменов }\end{array}$ & $\begin{array}{c}\text { Отменить государственные экзамены, } \\
\text { вернуть степень кандидата }\end{array}$ \\
\hline $\begin{array}{l}\text { святого } \\
\text { Владимира }\end{array}$ & $\begin{array}{c}\text { Вернуть прежний порядок испытания } \\
\text { в факультетах без перехода на предметную } \\
\text { систему } \\
\end{array}$ & $\begin{array}{c}\text { Отменить государственные экзамены, } \\
\text { можно ввести государственные } \\
\text { ведомственные экзамены }\end{array}$ \\
\hline Новороссийский & $\begin{array}{c}\text { Восстановить курсовые испытания } \\
\text { на прежних основаниях }\end{array}$ & Отменить государственные экзамены \\
\hline Юрьевский & $\begin{array}{c}\text { Восстановить переходные экзамены, } \\
\text { но не по курсовой системе }\end{array}$ & $\begin{array}{c}\text { Оставить государственные экзамены, } \\
\text { но с прежним порядком испытаний - } \\
\text { без программ министерства в виде } \\
\text { факультетских экзаменов } \\
\end{array}$ \\
\hline Варшавский & Сохранить порядок экзаменов & $\begin{array}{c}\text { Отменить государственные экзамены, } \\
\text { оставить только экзамены на ученые } \\
\text { степени }\end{array}$ \\
\hline
\end{tabular}

Как видно из таблицы, экзаменами в течение курса обучения и итоговыми государственными экзаменами были недовольны практически во всех университетах. В Московском, Петербургском, Харьковском университетах просили передать переходные экзамены в ведение факультетов, однако приурочить их к учебным планам. Отказ от курсовой системы обучения был декларирован только Юрьевским университетом, что вполне понятно, так как там всегда существовала предметная система обучения. При этом все остальные университеты скорее предпочитали вернуть порядок сдачи экзаменов, существовавший до устава 1884 г., порядок курсовой системы обучения, нежели полностью переходить на предметную. При господствовавшей в большинстве университетов идее о внедрении предметной системы обучения (о чём речь пойдет далее), выходило, что университеты, тем не менее, не готовы к её внедрению в полном смысле - с отсутствием ежегодных экзаменов.

Применительно к реформированию системы обучения интересен свод мнений, высказанных по поводу 10-го вопроса, который звучал так: «Какие меры могли бы привлечь студентов к более усердным, чем ныне, занятиям и поднять уровень получаемого ими университетского образования?» Профессора Санкт-Петербургского университета считали, что во время действия устава 1863 г. единственной заботой факультета был недостаток материальных средств, который и был единственной причиной недостаточно усердных занятий студентов, а после введения устава 1884 г. у факультетов «было отнято право самостоятельно распоряжаться, под контролем Совета, учебными делами. Они 
должны были вести преподавание по неподвижным учебным планам и программам, составленным иногда даже без всякого с их стороны участия» [25, ф. 14, оп. 25, д. 9, л. 14об]. Учебные планы, отличавшиеся многопредметностью, были приноровлены к получению студентами прав государственной службы (учитель гимназии), что лишало студента, не желающего получать таких прав, возможности выбора. Профессора даже считали, что обязательное посещение всех занятий вредно, и лучшим выходом видели переход к предметной системе [25, ф. 14, оп. 25, д. 9, л. 52об].

Среди университетов, выступивших за скорейший переход к предметной системе обучения как одной из первостепенных мер для улучшения уровня образования, были, кроме Санкт-Петербургского, Московский, Харьковский, Новороссийский и Юрьевский [16, ф. 733, оп. 154, д. 267]. Остальные высказывались осторожно, хотя и в Советах других университетов были профессора, ратовавшие за переход к предметной системе обучения. Так, профессор физики университета святого Владимира (наиболее консервативного) Г. Г. Де Метц полагал, что при единогласном решении основать «весь новый университетский строй на началах свободы выбора профессоров, деканов, ректора, свободы факультетского преподавания без мертвящего формализма министерских программ, на свободе студенческих организаций в их учебной жизни, то, казалось бы, свобода слушания лекций и предметная, а не курсовая система преподавания являются сами собой, как звено, замыкающее в одно стройное целое цепь университетских привилегий. Но вышло иначе. Большинство Совета стало отстаивать, что введение свободы слушания лекций и предметного преподавания нанесёт удар не только университету, но и русской общественной жизни, так как будто бы современная молодёжь всё ещё нуждается в опеке, в указании всяких мелочей её жизни, в инструкциях разного рода, без чего она может растеряться, облениться и не дойти до конечной цели, до завершения своего высшего образования, удостоверенного дипломом» [16, ф. 733, оп. 151, д. 264, л. 265об-266]. Основанием для отказа от перехода к предметной системе, следовательно, служило недоверие профессоров к студентам.

Как писал по этому поводу профессор физиологии Московского университета Л. 3. Мороховец, самим университетам необходимо было определиться, какое преподавание должно быть в университете: школьное, как того требовал устав, или академическое, каковое присуще университету [16, ф. 733, оп. 154, д. 266, л. 347]. Об этом же говорил профессор зоологии Н. Ю. Зограф, называя студентов не индивидуальными слушателями, а номером известного факультета и курса, чего не должно было быть. Необходимость перехода к предметной системе он обосновывал тем, что у студентов-естественников так много обязательных работ, что «если бы они исполняли эти работы, то для работ, производимых по личной инициативе, не осталось бы ни часа свободного времени» [16, ф. 733, оп. 154, д. 266, л. 319].

Можно сказать, что профессора, считавшие предметную систему панацеей, определённо идеализировали её. Такая идеализация была связана, прежде всего, с особенным недовольством уставом 1884 г., который «явился под двумя флагами: правительственной опеки и академической свободы» [3, с. 545], что явно противоречило друг другу.

Профессор физиологии университета святого Владимира С. И. Чирьев, который был далеко не сторонником университетской автономии и идеализации университета германского типа, в 1901 г. писал, что «устав 1884 г. сделал из университетов полусвободные-полузакрытые учреждения. С одной стороны, свобода не преподавания, а "преподавать", и свобода посещения лекций были доведены до крайностей» $[26$, с. 1]. Он критически относился к переходу на предметную систему обучения по германскому образцу, считая, что для её реализации необходима «известная культурность страны в западноевропейском смысле» и «известная зажиточность страны, дабы отцы были в состоянии обеспечить сына в течение известного времени и дать ему средства заниматься, не заботясь о куске насущного хлеба» $[27$, с. 13-14].

Некоторые профессора считали, что причиной неуспешной организации учебного процесса был не только и не столько устав 1884 г., а сама ментальность русского студента, не способствующая переходу на предметную систему, которая «мало согласуется с общим складом характера русского студента и предполагает, что все или, по крайней мере, большинство поступающих в университет ищут только знания, а не диплом. На деле же наблюдается как раз обратное» [16, ф. 733, оп. 154, д. 267, л. 698-698об]. О несоответствии германских образцов русскому менталитету говорил и профессор неорганической химии Новороссийского университета Е. Ф. Клименко, подчёркивая, что «там это возможно. Но у нас, при наших нравах, введение автономии и свободы выбора предметов едва ли может дать хорошие результаты» [5, ф. 45, оп. 11, д. 5 (1901), л. 158] в связи с отсутствием привычки к самостоятельной подготовке студентов. 
Против германской системы выступал С. И. Чирьев, об этом же писал в 1901 г. В. И. Вернадский, указывая на то, что ещё при обсуждении университетского устава в 1862 г. поднимался вопрос об отмене курсов, но подвергся правильной критике и не был введён [2, с. 10]. Действительно, предложения о введении «свободы учения» содержали проект князя Г. А. Щербатова (1858), который А. В. Никитенко назвал «трудом на ветер», а улучшения университета по этому проекту — «чистой утопией» [11, с. 91], проект М. А. Корфа (1861), Головнинский проект (1862), да и, вообще, эта идея витала в воздухе на рубеже 1850-х - 1860-х гг., однако в итоге в университетский устав 1863 г. не вошла. Но та обстановка, которая сложилась в университетах после принятия устава 1863 г., привела к распространению свободы слушания лекций, когда студенты могли посещать лекции любых профессоров, в том числе не своего факультета, но не все профессора считали этот порядок допустимым.

В. И. Вернадский, например, видел «корень всех зол» именно в порядках устава 1863 г., который привёл «к созданию не упругих и ученических планов, укоренившихся, к сожалению, в русских университетах» [2, с. 7]. А Л. 3. Мороховец напрямую высказывался о том, что именно устав 1863 г. привёл к тому положению вещей, когда студенты не желали заниматься: «Устав 1863 года уже заставил студентов составить свою собственную программу прохождения курсов с разделением предметов на нужные и ненужные: одни из коих слушались, по другим прочитывалось кое-что, а по третьим студенты даже к экзаменам не готовились... Такого рода отношение настолько укоренилось в студенчестве, что было по наследству передано и новому уставу» $[1$, ф. 445, оп. 2 , д. 88, л. 54].

Всколыхнувший профессорскую корпорацию пересмотр университетского устава в 1901 г. кончился тем, что материалы, полученные из университетов, поступили в специально созданную для их обсуждения комиссию [22], состоявшую из представителей министерства народного просвещения, других министерств и университетов, которая начала работу 30 сентября 1902 г. Впрочем, результата в виде введения предметной системы, которую в комиссии признали необходимой мерой для преобразования высшей школы, пришлось подождать.

Повторно вопрос о неотложных мерах по изменению ситуации в высшей школе возник во время революции 1905 г. В том же году «именным высочайшим указом 27 августа на обязанность и ответственность университетских советов возложены заботы о поддержании правильного хода учебной жизни» $[8$, ф. 402, оп. 4, д. 1287, л. 139], согласно которому Советы выработали свои проекты мер о восстановлении правильного хода учебной жизни, среди которых в обязательном порядке присутствовал пункт о свободе обучения [8, ф. 402, оп. 4, д. 1287, л. 140p] и необходимости перехода к предметной системе $[1$, ф. 445 , оп. 2 , д. 88, л. 170]. Этот пункт содержали проекты уставов, выработанные в Московском [12, ф. 781, ед. хр. 135, л. 7] и Санкт-Петербургском [14, с. 29] университетах в 1905 г.

Как объяснялось в постановлении Совета Московского университета, «существенная задача университетского преподавания заключается не только в том, чтобы сообщить студентам познания в избранных каждым из них отделах науки, но главным образом в том, чтобы пробудить в учащихся живой интерес к научной работе и, насколько возможно, познакомить их с приёмами научного исследования. Поэтому необходимо поставить в университете на должную высоту преподавание специальных отделов науки, которыми студенты могли бы заниматься, по собственному выбору, под ближайшим руководством профессоров. Что касается курсов обязательных, или лучше основных, общих для всех студентов данного факультета или отделения, то они имеют своей главной целью сообщение основных познаний в данной области науки, необходимых для дальнейших более специальных занятий студента. Поэтому, в проверке на экзамене должны подлежать только основные отделы науки. Число таких общих курсов не должно быть слишком велико, чтобы как можно менее стеснять свободные занятия студентов» [1, ф. 445, оп. 2 , д. 88, л. 170].

Физико-математический факультет Санкт-Петербургского университета на волне революции пошел ещё дальше: 9 декабря 1905 г. было принято постановление «О введении предметной системы» [12, ф. 781, ед. хр. 141] (оно вошло в качестве приложения в проект устава университета).

Циркулировавшие в профессорской корпорации надежды на переход к предметной системе в связи с положением в стране и принятием «Временных правил 27 августа 1905 г.», получили дальнейшее развитие в министерстве графа И. И. Толстого, вступившего в должность министра в ноябре 1905 г. Уже в январе 1906 г. профессора всех университетов (ректор и по одному профессору от каждого факультета) собрались в Петербурге на совещание по университетской реформе, материалы которого были вскоре опубликованы [23]. 
Bсе профессора были разделены на 4 комиссии, в ведении которых были главные вопросы: об управлении университетами, о личном составе, об учащихся и о преподавании. В состав последней комиссии, в которой разгорелись споры о предметной системе, вошли профессор зоологии Петербургского университета В. М. Шимкевич, профессор зоологии Московского университета М. А. Мензбир, профессор терапии Варшавского университета В. В. Кудревецкий, профессор физиологии Харьковского университета В.Я. Данилевский, профессор терапии Новороссийского университета П. А. Вальтер, профессор сравнительного языкознания и санскрита Казанского университета А. И. Александров, профессор семитских языков Юрьевского университета А. М. фон Бульмеринг, профессор хирургии Юрьевского университета В. Г. Цеге-фон-Мательфель, профессор медицинской химии Томского университета Ф. К. Крюгер и профессор физики университета святого Владимира Г. Г. Де Метц, под председательством В. М. Шимкевича.

На заседании комиссии Г. Г. Де Метц указывал, что проект устава, рассматриваемый комиссией, совершенно не определяет точно, что такое предметная система, которая при установлении многопредметности в преподавании принесёт только вред. В связи с этим, он предлагал установить небольшие циклы наук [23, с. 76].

Профессор истории Юрьевского университета А. Н. Ясинский вообще считал, что без индивидуализации научной работы (что не было предусмотрено в проекте) предметная система невозможна, а основная проблема курсовой системы решится, если дозволить студентам сдавать проваленный экзамен вторично, без потери года. Он говорил о том, что при государственных нуждах на выпуск специалистов индивидуализация вообще невозможна, да и русские студенты в массе своей всё равно не способны самостоятельно выработать правильный план учения, поэтому будут вынуждены использовать факультетские планы. Чтобы решить этот вопрос, он предлагал заменить все статьи о преподавании одной статьей из устава Дерптского университета 1865 г.: «Постановления об учебных курсах излагаются в особых правилах, составленных факультетами» [23, с. 77], предоставив, таким образом, каждому университету самостоятельно решать, какая система ему больше подходит.

Этого мнения придерживался и профессор математики Харьковского университета В. А. Стеклов. А ректор Московского университета А. А. Мануилов, обратив внимание на то, что одним из главных вопросов является вопрос автономии университетов, считал, что при автономии решение о введении или невведении предметной системы необходимо передать университетам, так как «преподавание - дело живое».

Профессор математики Варшавского университета Г. Ф. Вороной подчеркивал, что «интересы преподавания могут быть одинаково обеспечены и при курсовой системе, и при предметной. Разница только в том, что курсовая система делает больше удобств для согласования чтения лекций с экзаменами. С этой точки зрения введение предметной системы доставит много забот и лишних хлопот профессорам и деканам. Предметная система вводится потому, что этого добиваются с давних пор студенты, которые понимают предметную систему не совсем так, как её понимают обыкновенно профессора. Следует предоставить факультетам возможность постепенно перейти от курсовой системы к предметной, в зависимости от запросов и условий университетской жизни» [23, с. 78].

В итоге, большинство голосов решило оставить практически без изменений статьи проекта, касающиеся предметной системы, то есть ввести её в университетах. Сам министр И. И. Толстой в своих воспоминаниях писал, что «введение в университетах предметной системы преподавания взамен курсовой составляло давнишнее pium dexiderium ${ }^{1}$ подавляющего большинства факультетов всех русских “храмов науки”» [12, ф. 781, ед. хр. 568, л. 98].

Введение предметной системы в российских университетах, конечно, не могло (а в итоге и не смогло) решить накопившиеся проблемы, которых было слишком много. Для успешного перехода на предметную систему требовалось больше, чем воля профессоров и указ министерства народного просвещения («Правила 12 июня 1906 г.», которые передали в руки факультетов принятие решения о сдаче экзаменов и упразднили привязку дисциплин к курсам обучения). Основным препятствием для перехода на предметную систему оказалось то обстоятельство, которое когда-то сыграло решающую роль в привлечении студентов в университеты в начале XIX в.: получение чина по Табели о рангах, связанного с университетским дипломом. А для получения этого преимущества требовались университетские дипломы если не единого образца, то имевшие одинаковый перечень сданных экзаменов

\footnotetext{
${ }^{1}$ Благое пожелание.
} 
по прослушанным курсам, что при предметной системе обучения, дававшей право выбирать не только очерёдность курсов, но и их состав, было нереализуемо. В результате, уже через несколько лет после принятия «Правил 12 июня» министерством были утверждены перечни полукурсовых и окончательных испытаний, что значительно редуцировало предметную систему в университетах.

Таким образом, профессора российских университетов в большинстве своём видели предметную систему обучения некоей панацеей для накопившихся в университетском образовании проблем. Поэтому при любой возможности они выражали своё мнение на этот счёт, в особенности во время диалога с министерством народного просвещения. Несмотря на то, что разговоры о предметной системе начались давно, только революция 1905 г. смогла подтолкнуть власти к принятию решительных мер в данной области. Однако переход на предметную систему обучения в условиях того времени оказался отличным от того, на что рассчитывали профессора.

\section{СПИСОК ИСТОЧНИКОВ И ЛИТЕРАТУРЫ}

1. Архив Российской академии наук (АРАН).

2. Вернадский В. Об основаниях университетской реформы. М., 1901.17 с.

3. Виноградов П. Г. Учебное дело в наших университетах // Вестник Европы. 1901. Кн. 10. С. 537-573.

4. Вишленкова E. A. Русские профессора: университетская корпоративность или профессиональная солидарность. М.: Новое литературное обозрение, 2012. 650 с.

5. Государственный архив Одесской области (ГАОО).

6. Грибовский М. В. Профессорско-преподавательский корпус императорских университетов как социальнопрофессиональная группа российского общества. 1884 г. — февраль 1917 г.: автореф. дис. ... д-ра ист. наук: 07.00.02. Томск, 2018. $43 \mathrm{c}$.

7. Жуковская T. Н., Любезников О. А. Правительственная политика и корпорация Петербургского университета в дореформенный период: основные итоги и проблемы изучения // Клио. 2013. № 10 (82). С. 26-35.

8. Исторический архив Эстонии (ИАЭ).

9. Костина Т. В. Мир университетского профессора Казани: 1804-1863: дис. ... канд. ист. наук: 07.00.02. Казань, 2007. $226 \mathrm{c}$.

10. Национальный архив республики Татарстан (НАРТ).

11. Никитенко А. В. Записки и дневник: в 3 т. Т. 2. М.: Госполитиздат, 1956.652 с.

12. Отдел рукописей Российской национальной библиотеки (ОР РНБ).

13. Петров Ф. А. Формирование системы университетского образования в России: в 4 т. Т. 3: Университетская профессура и подготовка устава 1835 года. М.: Изд-во Моск. ун-та, 2003. 480 с.

14. Проект главных положений устава университета, выработанный Санкт-Петербургским университетом. СПб., $1905.58 \mathrm{c.}$

15. Профессорско-преподавательский корпус российских университетов. 1884-1917 гг.: исследования и документы / под ред. М. В. Грибовского, С. Ф. Фоминых. Томск: Изд-во ТГУ, 2012. 368 с.

16. Российский государственный исторический архив (РГИА).

17. Рождественский С. В. Исторический обзор деятельности министерства народного просвещения. 1802-1902. СПб., $1902.785 \mathrm{c}$.

18. Ростовщев E. А., Баринов Д. А. Петроградская университетская корпорация в годы I Мировой войны: опыт коллективного портрета // Клио. 2017. № 10 (130). С. 136-144.

19. Ростовиев E. А. Столичный университет Российской империи: учёное сословие, общество и власть (вторая половина XIX - начало XX в.). М.: Полит. энцикл., 2017. 903 с.

20. Сазонова Л. А. Повседневность университетского профессора Казани, 1863-1917 гг.: дис. ... канд. ист. наук: 07.00.02. Казань, 2009. 217 c.

21. Сословие русских профессоров. Создатели статусов и смыслов: кол. монография / под ред. Е. А. Вишленковой, И. М. Савельевой. М.: Изд. дом ВШЭ, 2013. 386 с.

22. Труды высочайше учреждённой комиссии по преобразованию высших учебных заведений. Вып. 1-5. СПб., 1903.

23. Труды Совещания профессоров по университетской реформе, образованного при Министерстве народного просвещения под председательством министра графа И. И. Толстого в январе 1906 г. СПб., 1906. 343 с.

24. Феофанов A. M. Социальный портрет профессоров Московского университета второй половины XVIII первой четверти ХІХ в. // Вестн. Волжского ун-та им. В. Н. Татищева. 2013. № 1 (12). С. 168-179.

25. Центральный государственный исторический архив Санкт-Петербурга (ЦГИА СПб).

26. Чирьев С. Проект реформы высшего образования. Киев, 1901. 22 с.

27. Чирьев С. Проекты преобразования наших высших и средних школ. Киев, 1906. 27 с. 
Жарова Екатерина Юрьевна, кандидат биологических наук, соискатель отдела историографии и источниковедения истории науки и техники ФГБУН «Институт истории естествознания и техники Им. С. И. Вавилова РАН» 125315, Россия, г. Москва, ул. Балтийская, д. 14 E-mail: zharova_ekaterina@bk.ru

\section{E.Yu. Zharova \\ PROFESSORIAL CORPORATION AND REFORM OF THE EDUCATION SYSTEM AT UNIVERSITIES AT THE TURN OF THE XIX-XX CENTURIES}

DOI: $10.35634 / 2412-9534-2020-30-4-607-615$

In the late XIX - early XX centuries the Ministry of Education could no longer reform education system without relying on the opinion of the professorial corporation. The largest sessions created by the Ministry to find out the point of view of professors on the most problematic issues of university life took place in 1901 and 1906. The purpose of these sessions was to revise the university statute of 1884 , but neither in the first nor in the second case did the new statute appear. The materials of the first session were buried in the Ministry, but according to the results of the second session, a subject educational system was proclaimed. Under the conditions of that time (1906), along with other easing of university administration, it was a significant step forward towards university autonomy and the freedom of education expressed in the subject system. This article provides an analysis of the opinions of professors of universities of the Russian Empire which were gathered during those two sessions and reflecting the points of view of the professorial corporation about the reform of the educational system.

Keywords: professors, Universities, Russian Empire, reform, subject system of education.

\section{REFERENCES}

1. Arhiv Rossijskoj akademii nauk (ARAN) [Archive of Russian Academy of Science].

2. Vernadskij $V$. Ob osnovaniyah universitetskoj reformy [About the basements of the University reform]. Moscow, 1901, 17 p. (In Russian).

3. Vinogradov P. G. Uchebnoe delo v nashih universitetah [Educational affair in our Universities]. Vestnik Evropy [Herald of Europe], 1901, no. 10, pp. 537-573. (In Russian).

4. Vishlenkova E. A. Russkie professora: universitetskaya korporativnost' ili professional'naya solidarnost' [Russian professors: university corporate or professional solidarity]. Moscow, "Novoe literaturnoe obozrenie" Publ., 2012, 650 p. (In Russian).

5. Gosudarstvennyj arhiv Odesskoj oblasti (GAOO) [State Archive of Odessa Region].

6. Gribovskij M. V. Professorsko-prepodavatel'skij korpus imperatorskih universitetov kak social'no-professional'naya gruppa rossijskogo obshchestva. $1884 \mathrm{~g}$. - fevral' $1917 \mathrm{~g}$. [The corps of professors and teachers in imperial Universities as social and professional group of Russian society]: avtoref. dis. ... d-ra ist. nauk [Abstract of the thesis for obtaining a degree of Doctor of Science in History]: 07.00.02. Tomsk, 2018, 43 p. (In Russian).

7. Zhukovskaya T. N., Lyubeznikov O. A. Pravitel'stvennaya politika i korporaciya Peterburgskogo universiteta v doreformennyj period: osnovnye itogi i problemy izucheniya [The governmental politics and the corporation of Petersburg University at pre-reform period: main resultst and problems of studying]. Klio, 2013, no. 10 (82), pp. 2635. (In Russian).

8. Istoricheskij arhiv Estonii (IAE) [Historical Archive of Estonia].

9. Kostina T. V. Mir universitetskogo professora Kazani: 1804-1863 [The world of University professor of Kazan: 1804-1863]: dis. ... kand. ist. nauk [The thesis for obtaining a degree of Candidate of Science in History]: 07.00.02. Kazan, 2007, 226 p. (In Russian).

10. Nacional'nyj arhiv respubliki Tatarstan (NART) [National Archive of Tatrstan Republic].

11. Nikitenko A. V. Zapiski i dnevnik [Notes and the diary]. V. 2. Moscow, "Gospolitizdat” Publ., 1956, 652 p. (In Russian).

12. Otdel rukopisej Rossijskoj nacional'noj biblioteki (OR RNB) [Department of Manuscripts of Russian National Library].

13. Petrov F. A. Formirovanie sistemy universitetskogo obrazovaniya v Rossii [The formation of the system of University education in Russia]. V 4-h tt. T. 3: Universitetskaya professura i podgotovka ustava 1835 goda [University professors and preparing the Statute of 1835]. Moscow, Moscow University Press, 2003, 480 p. (In Russian).

14. Proekt glavnyh polozhenij ustava universiteta, vyrabotannyj Sankt-Peterburgskim universitetom [The projest of the main statements of the University statute, created by Saint-Petersburg University]. Saint Petersburg, 1905, 58 p. (In Russian). 
15. Professorsko-prepodavatel'skij korpus rossijskih universitetov. 1884-1917 gg.: issledovaniya i dokumenty [The corps of professors and teachers of Russian Universities. 1884-1917: researches and documents]. Ed. of M. V. Gribovskij, S. F. Fominyh. Tomsk, Tomsk State University Press, 2012, 368 p. (In Russian).

16. Rossijskij gosudarstvennyj istoricheskij arhiv (RGIA) [Russian State Historical Archive].

17. Rozhdestvenskij $S$. $V$. Istoricheskij obzor deyatel'nosti ministerstva narodnogo prosveshcheniya [Historical review of the action of the Ministry of Education]. 1802-1902. Saint Petersburg, 1902, 785 p. (In Russian).

18. Rostovcev E. A., Barinov D. A. Petrogradskaya universitetskaya korporaciya v gody I Mirovoj vojny: opyt kollektivnogo portreta [University corporation of Petrograd during I World War: the experience of collective portrait]. Klio, 2017, no. 10 (130), pp. 136-144. (In Russian).

19. Rostovcev E. A. Stolichnyj universitet Rossijskoj imperii: uchenoe soslovie, obshchestvo i vlast' (vtoraya polovina XIX - nachalo XX v.) [The capital University of the Russian Empire: academic class, society and authority (the second half of 19 - the beginning of 20 century)]. Moscow, "Politicheskaya enciklopediya" Publ., 2017, 903 p. (In Russian).

20. Sazonova L. A. Povsednevnost' universitetskogo professora Kazani, 1863-1917 gg. [The daily routine of University professor of Kazan: 1863-1917]: dis. ... kand. ist. nauk [The thesis for obtaining a degree of Candidate of Science in History]: 07.00.02. Kazan, 2009, 217 p. (In Russian).

21. Soslovie russkih professorov. Sozdateli statusov i smyslov: kollekt. monografiya [The class of Russian professors. Creators of statuses and meanings: collective monograph]. Ed. of E. A. Vishlenkova, I. M. Savel'eva. Moscow, VSHE Press, 2013, 386 p. (In Russian).

22. Trudy vysochajshe uchrezhdennoj komissii po preobrazovaniyu vysshih uchebnyh zavedenij [Works of the supremely established committee for changing of higher education institutaions ]. Vyp. 1-5. Saint Petersburg, 1903. (In Russian).

23. Trudy Soveshchaniya professorov po universitetskoj reforme, obrazovannogo pri Ministerstve narodnogo prosveshcheniya pod predsedatel'stvom ministra grafa I. I. Tolstogo v yanvare 1906 goda [Works of the conference of professors about University reform, created by the Ministry of Education chaired by the minister count I. I. Tolstoy in January 1906]. Saint Petersburg, 1906, 343 p. (In Russian).

24. Feofanov A. M. Social'nyj portret professorov Moskovskogo universiteta vtoroj poloviny XVIII — pervoj chetverti XIX v. [Social portrait of professors of Moscow University of the second half of 18 - the first quarter of 19 century]. Vestnik Volzhskogo universiteta im. V. N. Tatishcheva [Herald of Volzhsky University named after V. N. Tatishchev], 2013, no. 1 (12), pp. 168-179. (In Russian).

25. Central'nyj gosudarstvennyj istoricheskij arhiv Sankt-Peterburga (CGIA SPb) [Central State Historical Archive of Saint Petersburg].

26. Chir'ev S. Proekt reformy vysshego obrazovaniya [The project of the reform of higher education]. Kiev, 1901, $22 \mathrm{p.}$ (In Russian).

27. Chir'ev S. Proekty preobrazovaniya nashih vysshih i srednih shkol [The projects of the transformation of our higher and secondary schools]. Kiev, 1906, 27 p. (In Russian).

Received 12.04.2020

Zharova E. Yu., Candidate of Biology, Applicant for a Doctorate

of Department of Historiography and Source Study of the History of Science and Technology

S. I. Vavilov's Institute for the History and Technology of RAS

Baltiyskaya st., 14, Moscow, Russia, 125315

E-mail: zharova_ekaterina@bk.ru 